\title{
Medievalista
}

Online

$31 \mid 2022$

Número 31

\section{Monges e mosteiros galegos em Portugal (séculos XII-XV)}

Galician Monks and Monasteries in Portugal (12th - 15th Centuries)

Francisco Javier Pérez Rodríguez

\section{(2) OpenEdition}

\section{Journals}

\section{Edição electrónica}

URL: https://journals.openedition.org/medievalista/5104

ISSN: 1646-740X

\section{Editora}

Instituto de Estudos Medievais - FCSH-UNL

\section{Refêrencia eletrónica}

Francisco Javier Pérez Rodríguez, «Monges e mosteiros galegos em Portugal (séculos XII-XV)»,

Medievalista [Online], 31 | 2022, posto online no dia 01 janeiro 2022, consultado o 02 fevereiro 2022. URL: http://journals.openedition.org/medievalista/5104

Este documento foi criado de forma automática no dia 2 fevereiro 2022.

Mediavalista está licenciado com uma Licença Creative Commons - Atribuição-NãoComercial 4.0 Internacional 


\title{
Monges e mosteiros galegos em Portugal (séculos XII-XV)
}

Galician Monks and Monasteries in Portugal (12th - 15th Centuries)

\author{
Francisco Javier Pérez Rodríguez
}

\section{NOTA DO EDITOR}

Data recepção do artigo / Received for publication: 5 de Dezembro de 2020. Data aceitação do artigo / Accepted in revised form: 8 de Julho de 2021

1 A presença de mosteiros galegos no reino de Portugal tem sido abordada, em termos gerais, de forma individual para cada caso particular. É o caso, por exemplo, do estudo sobre Santa Maria de Oia por E. Portela e $\mathrm{M}^{\mathrm{a}}$ Carmen Pallares ${ }^{1}$ ou do meu sobre Toxosoutos $^{2}$ onde se analisa rapidamente o domínio português desses cenóbios com base na documentação conservada de cada um. O único estudo que aborda extensamente o domínio português de um cenóbio galego é a tese doutoral de Ana Paula Leite Rodrigues, orientada por Ermelindo Portela, apresentada em 2015 e recentemente publicada ${ }^{3}$. Definitivamente, Oia é o único mosteiro galego capaz de alicerçar um trabalho deste tipo, pois a documentação dos outros cenóbios é consideravelmente menor. Ainda assim, vale a pena averiguar que mosteiros galegos constituíram património em Portugal, tal como comprova neste momento Víctor Rodríguez Muñiz relativamente a vários mosteiros femininos na diocese tudense ${ }^{4}$. Estes e outros trabalhos, que serão mencionados a seguir, apoiam este estudo.

\section{Mosteiros galegos com bens em Portugal}

O primeiro facto que se observa ao enumerar os mosteiros galegos que certamente tiveram bens em Portugal é a sua escassez: Antealtares, Toxosoutos, Oia, Donas, Tomiño, Albeos, Melón, Ramirás, Celanova e Montederramo e a abadia secular de Santa Maria de Vilaza. A localização destes mosteiros mostra claramente que são os cenóbios 
da Galiza meridional os que conseguem implementar o seu domínio a sul da fronteira. Muito provavelmente a lista poderia ser ampliada com mais algum mosteiro desta área, pois a proximidade geográfica de Rebordáns, nos arredores de Tui, de Budiño ou do padroado agostiniano de Grou com Portugal, torna-os suscetíveis de terem recebido alguma doação no reino vizinho.

3 Na fronteira entre Galiza e Portugal destacamos a diferença numérica entre os mosteiros na diocese de Tui e os de Ourense. Nesta última, o número de mosteiros é muito menor e são - exceto nos casos de Montederramo, Celanova e Ramirás - de menor dimensão: dois pequenos padroados agostinianos - Grou e Porqueira - um padroado celanovês - Ribeira - e duas abadias seculares unidas desde muito cedo ao bispado auriense no vale do Tâmega - Vilaza e Servoi. Os protagonistas tudenses, com a exceção dos cistercienses de Oia e Melón, também não são mosteiros grandes. Apesar de serem todos beneditinos - salvo a abadia secular de Crecente - apenas três abadias femininas tiveram seguramente bens em Portugal: Donas, Tomiño e Albeos.

\section{Situação e caracterização dos bens monásticos galegos em Portugal}

4 Os bens que os mosteiros recém mencionados possuem no reino português têm mais visibilidade na fronteira e escasseiam à medida que se avança para o sul. A maioria deles localiza-se entre os rios Minho e Lima, a partir dos quais somente alguns se estendem até ao Douro. A sul deste, apenas Santa Maria de Oia está presente com certeza na Estremadura portuguesa a partir do século XII, pois nada se sabe sobre o que foi entregue a Celanova em Coimbra e seus arredores no século X.

5 Tal como mencionado antes, os bens monásticos galegos concentram-se maioritariamente no Norte, entre os rios Minho e Lima, mais concretamente nas margens do rio Minho, nos termos dos atuais concelhos de Caminha, Vila Nova de Cerveira, Valença e Melgaço. Somente aqui confluem os domínios de várias casas, constituindo-se assim um espaço português mais significativo para monges e monjas galegos. Fora deste espaço, as propriedades são verdadeiras exceções, apesar da importância que possam ter tido.

6 Por este motivo, reafirmamos a importância da fronteira do rio Minho relativamente à raia seca de Ourense, cujos fatores estarão relacionados não só com a superioridade numérica de mosteiros próximos de Portugal no bispado de Tui do que no de Ourense, como também com a provável superioridade demográfica e económica do primeiro sobre o segundo. Devido ao facto de os mosteiros receberem e adquirirem bens nas suas áreas próximas, Oia, Tomiño e Albeos estenderam os seus domínios para além do rio Minho, chegando até Ramirás e, provavelmente, até Celanova. Daí a escassa presença em Trás-os-Montes, onde apenas encontramos Montederramo, no vale do Tâmega.

7 Apenas quatro mosteiros galegos possuíram unidades de exploração suficientemente significativas no reino de Portugal: San Paio de Antealtares, San Xusto de Toxosoutos, Santa Maria de Montederramo e - o mais importante - Santa Maria de Oia. A estes podemos acrescentar São Salvador de Celanova, recetor de várias doações ainda antes da constituição da monarquia portuguesa e que, pelo menos a partir do século XIII, manteve um padroado em Refojos: São Salvador de Monte Córdova. 
8 A maioria destes centros dominiais tem a sua origem nas grandes doações feitas pela alta aristocracia ou pela própria monarquia. Tirando as que foram doadas a Celanova, San Paio de Antealtares é o primeiro mosteiro galego a receber uma grande doação em terras portuguesas. A doação efetuada em 985 pelo conde D. Telo Alvites e a sua mulher, D. Mumadona, implicou a instalação sólida do cenóbio em Ribeiro de Avia ${ }^{5}$. Graças à generosidade dos condes, o mosteiro compostelano estende o seu domínio pelas margens do rio Lima ${ }^{6}$ até às localidades de Paradela, Mazarefes e também até à que seria a futura cidade de Ponte de Lima, as três confirmadas a Antealtares por Fernando I em 10657. A doação incluía mais alguns bens e, para além desta doação, San Paio deve ter recebido outras inclusive a sul do rio Lima, tal como se demonstra em 1136 quando, para manter os seus direitos eclesiásticos sobre a igreja de São João da Ribeira - da qual dependia Paradela -entrega ao arcebispo de Braga três quartos de São Mamede de Este, "que est circa Bracaram", pelo que nessa vila possui o mosteiro e mais três casais, sendo um deles o de "Abbatibus", em Domez ${ }^{8}$, que formava parte da doação do conde D. Telo9.

9 O domínio português de Montederramo também tem a sua origem numa doação nobiliária, uma vez que D. Afonso Henriques entrega, em 1128, a villa de Penas Iuntas a Fernando Anaias em Vilar de Peregrinos ${ }^{10}$. É este o documento conservado pelo mosteiro, embora não haja registo da entrega da localidade que o próprio Fernando Anaias ou os seus descendentes teriam feito posteriormente ao mosteiro. Este organizou a sua granja-padroado ${ }^{11}$ em Cidões, a partir de onde governava o couto que se estendia ao conjunto da freguesia de Vilar de Peregrinos e desde onde teria incrementado o seu património nos séculos seguintes através dos mecanismos habituais ${ }^{12}$.

San Xusto de Toxosoutos é o único mosteiro galego que regista uma doação direta dos reis de Portugal ${ }^{13}$, pois em 1136 D. Afonso Henriques entrega ao mosteiro o couto de Paredes na foz do rio Lima, freguesia de Meadela. O principal interesse dos monges da ria de Noia para se estabelecerem no local era basicamente o abastecimento de sal, tal como demonstram os acordos assinados no século XIII - um pelos próprios couteiros e outro por São Martinho de Tibães. O privilégio outorgado por D. Afonso Henriques foi sucessivamente confirmado pelos seus descendentes, pelo menos no século XIII ${ }^{14}$.

11 Curiosamente, Santa Maria de Oia, sem dúvida alguma o mosteiro com mais domínios portugueses entre os cenóbios galegos, deve a constituição dos seus centros mais destacados às grandes doações. Os cistercienses de Oia tiveram até cinco granjas em Portugal: duas delas no espaço habitual dos seus irmãos galegos na margem do rio Minho - Silva e Chamosinhos, no termo de Valença - e outras três a sul do rio Douro Fanga da Fé, Enxara e Atouguia. Apenas Fanga da Fé tem a sua origem numa doação de uma personagem relevante: o primeiro monarca português, D. Afonso Henriques ${ }^{15}$. Ao contrário dos quatro centros analisados até agora, as granjas de Silva, Chamosinhos e Atouguia parecem terem sido organizadas por Santa Maria de Oia, continuando a doutrina cisterciense. $\mathrm{O}$ número de propriedades em ambas as zonas seria o suficiente para que o mosteiro chegasse a constituí-las como tal. Assim o demonstra Paula Leite Rodrigues, para a de Silva, ao expor como o mosteiro possuía trinta e sete casais e meio, para além de outras propriedades nas freguesias do atual termo de Valença ${ }^{16}$.

12 Mais surpreendente é o caso de Atouguia, apelidada da Baleia desde a Baixa Idade Média, junto à península de Peniche, que conforma um núcleo afastado do outro centro estremenho de Oia - Fanga da Fé e Enxara ${ }^{17}$. Este distingue-se por ser posterior e pela sua modéstia inicial, uma vez que em 1220 o mosteiro apenas possuía ali "unas marinas 
et unam casam et unam quairelam" que seriam a base da granja do mosteiro documentada em $1323^{18}$. A presença de Oia em Atouguia está relacionada com a grande presença de galegos na costa de Peniche e na própria Atouguia. Com base no estudo sobre a comarca de óbidos ${ }^{19}$, Manuela Santos Silva relaciona esta presença com a isenção de impostos concedida a trinta pescadores por D. Sancho IV de Castela, em 1286. Parece, pois, mais lógico relacionar a origem dos bens com as doações feitas pela comunidade procedente do próprio porto de Oia ou da costa próxima ao mosteiro, entre Baiona e A Guarda, seguindo uma tradição familiar ou uma devoção especial dos pescadores que ali se estabeleceram. A granja de Atouguia teria, desta forma, a mesma origem que a de Silva ou que a de qualquer outra exploração monástica semelhante da Galiza ou de Portugal.

Por último, com San Salvador de Celanova regressamos a um domínio monástico que se estende por terras de Portugal anterior à formação do reino por D. Afonso Henriques. Nas doações feitas pelo próprio São Rosendo e pela sua família à nova fundação incluem-se vários bens no território do futuro reino português - desde a margem esquerda do Minho até Coimbra, passando pelas terras do Porto ${ }^{20}$, às quais se acrescentaram, ao longo do século $\mathrm{X}$, outras de menor importância como, em Valadares, uma pesqueira no Minho doada por D. Ramiro II ou uma casa e uma herdade junto a esse mesmo rio ${ }^{21}$. Após um período sem doações ou aquisições, durante o século XI, em 1108 Celanova volta a fazer uma aquisição em Portugal quando o conde Nuño Váquez e a sua mulher, a condessa Fronille Sánchez, doam ao mosteiro as herdades que a condessa Dona Guntrode tinha tido em Caminha ${ }^{22}$.

14 A escassíssima documentação conservada de Celanova nos séculos XII e XIII impede-nos de saber o que aconteceu com o seu domínio praticamente em qualquer parte e, por este motivo, desconhece-se o que aconteceu aos bens alto-medievais legados ao cenóbio. É possível que nessa época Monte Córdova pertencesse a Celanova, embora a sua dependência não seja confirmada até $1241^{23}$. Neste ano, o mosteiro de Celanova ganhava o pleito que mantinha com D. Sancho II, sendo-lhe atribuídos a igreja e os bens de Monte Córdova em troca da renúncia aos seus direitos sobre Castro Laboreiro ${ }^{24}$. Apesar disso, nas inquirições de 1258 afirma-se que a ecclesia Sancti Salvatoris de Monte Corduba é do rei de Portugal, sem mencionar Celanova em nenhum momento ${ }^{25}$. Trinta anos depois, nas inquirições gerais de D. Dinis, a casa matriz volta a desaparecer, havendo apenas a indicação de que o couto é dessa egreja-Monte Córdova ${ }^{26}$.

15 Já no século XV, em 1460, D. Afonso V de Portugal recorda a disputa de Castro Laboreiro entre o cenóbio e o monarca, a qual tinha terminado mediante um acordo no qual Celanova renunciava à localidade em troca do padroado, bens e rendas de Monte Córdova $^{27}$.

16 Desta forma, São Salvador de Monte Córdova também tem a sua origem numa doação real em virtude da renúncia dos direitos celanoveses sobre Castro Laboreiro. A partir de 1241, o mosteiro estabelece ali um padroado autónomo de que apenas há escassos dados, embora, segundo as inquirições régias e também em 1460, estivesse acoitado. As primeiras mostram que chegou a constituir um domínio com certa importância talvez por ter ficado com alguns dos bens outorgados a Celanova no século X.

Os restantes mosteiros galegos não parecem ter formado nenhuma granja, padroado ou centro dominial em território português, seja porque nenhum recebeu uma doação da monarquia portuguesa, seja porque as propriedades que tiveram no reino de Portugal, excetuando-se as de Tomiño, foram muito escassas ou de importância secundária. 
ico cenóbio galego, cujo domínio a sul do Minho é comparável ao cisterciense de Oia em termos de propriedades no entre Douro e Minho, é o feminino de Santa Maria de Tomiño. Graças aos inventários de bens mandados fazer pelo cabido de Tui em princípios do século XVI, sabemos que o mosteiro chegou a possuir trinta casais entre o Minho e Lima, para além de outros bens menores, ampliando o seu domínio a sul deste rio até às proximidades de Braga e Porto - embora com uma presença muito menor neste espaço ${ }^{28}$. Ao contrário de Oia ou Montederramo, Tomiño não organizou nenhuma granja em território português, provavelmente devido à proximidade geográfica do mosteiro ao núcleo principal dos seus bens no reino vizinho, localizados em torno a Vila Nova da Cerveira, na margem minhota oposta, praticamente em frente ao próprio cenóbio.

19 A presença dos restantes mosteiros galegos em Portugal é muito mais modesta. Episódica é a de São Salvador de Barrantes, centrada em torno a Vila Nova da Cerveira; em 1258 apenas possuía dois casais: um em Sapardos - que acabava de vender - e outro - despovoado - em São Cibrão ${ }^{29}$. O mosteiro feminino de Santa Baia das Donas nos princípios do século $\mathrm{XV}$, quando foi suprimido e anexado à catedral de Tui, possuía dois casais na freguesia de S. Pedro de Gondarém e outras herdades isoladas nesta mesma paróquia ${ }^{30}$.

De igual modo, o mosteiro feminino de Ramirás também reúne o seu património português em torno à vila de Melgaço, destacando-se os casais ou as localidades de Barcia e Rial ${ }^{31}$. Na mesma zona, também se concentrariam as propriedades de San Salvador de Albeos, a um passo da vila de Melgaço, com o Minho no meio. Sabe-se da sua existência graças ao processo instruído em finais do século XV pela observância de San Benito de Valladolid à sua abadessa ${ }^{32}$.

21 Das posses portuguesas do mosteiro cisterciense de Melón, afirma Isabel Beceiro que "foram sempre de escassa entidade" ${ }_{33}$, ou seja, pouco significativas, ao contrário do seu congénere de Montederramo que, para além da granja de Cidões, teve bens no termo de Monforte de Rio Livre, no outro lado da fronteira, e em Coura $^{34}$ pelo menos a partir do século XIV.

Por último, a abadia secular de Vilaza tinha as suas propriedades portuguesas próximas da sua sede, em terras de Chaves, chegando a disputar, em meados do século XIII, a localidade de Mairos no reino vizinho, impedindo que os seus cidadãos fossem julgados pelo juiz de Rio Livre ${ }^{35}$. Adicionalmente, consta que tinha um casal na freguesia de Santo Estêvão, em Chaves ${ }^{36}$.

23 A origem de grande parte destes bens estaria nas doações efetuadas maioritariamente pelos próprios membros dos conventos monásticos às instituições em que tinham professado. Assim demonstram as doações recebidas por Oia e Ramirás, e as propriedades portuguesas de Tomiño. A estas doações juntar-se-iam outras de personagens que, por devoção ou pela sua relação especial com o cenóbio, decidiam fazer uma oblação à casa na hora da sua morte. Seria o caso dos párocos que serviam as freguesias portuguesas com grande presença de Oia ou o caso dos aristocratas com bens em ambos os lados do Minho, como os Velho ou os Cerveira estudados por Ana Paula Leite Rodrigues ${ }^{37}$. 


\section{A política da monarquia portuguesa em relação aos mosteiros galegos}

24 À luz do exposto, a política de doações aos mosteiros galegos pelos monarcas portugueses caracteriza-se por três aspetos: a sua escassez, a distância dos lugares doados face aos centros beneficiados e as efetuadas apenas pelo primeiro rei de Portugal, D. Afonso Henriques. Esta mínima generosidade da monarquia para com as entidades eclesiásticas afastadas do seu reino é explicada pela própria dinâmica política gerada pela independência lusa em relação à Galiza e a Leão.

Duvido que doações tão pontuais devam "ser entendidas como parte de uma estratégia clara de captação de apoios com o fim de tentar consolidar a presença portuguesa nos territórios de Límia e Toronho" ${ }^{38}$. Se, na realidade, D. Afonso Henriques tivesse esta intenção, não se compreende que Celanova, cujo grande domínio senhorial ladeava a fronteira do seu reino, não recebesse nenhuma doação - já para não falar da todopoderosa sede compostelana ou da mais modesta de Ourense - e preferisse, em alternativa, a aliança com Oia e Toxosoutos ${ }^{39}$. Face a esta possibilidade, a autora citada no início do presente parágrafo fornece uma razão mais plausível, já comentada, para a doação a Oia, no termo de Torres Vedras: a presença de repovoadores galegos na zona, que estaria também na origem dos bens detidos pelo mosteiro em Atouguia ${ }^{40}$.

Doações à parte, a política da monarquia portuguesa face aos mosteiros galegos com bens no seu reino não se diferencia muito da que praticava com os seus próprios cenóbios: a confirmação de bens ${ }^{41}$, a concessão de isenção de taxas ou impostos ${ }^{42}$, ou a intervenção para resolver os pleitos que os monges apresentam na corte. Esta "normalidade" da atuação dos reis de Portugal em relação aos domínios monásticos galegos no seu reino, assim como a coincidência dos seus problemas com os contemporaneamente sofridos na Galiza foram apontados, por exemplo, por Pablo Otero-Piñeyro ou por Isabel Beceiro para todo o período medieval ${ }^{43}$.

Especialmente revelante, neste sentido, é o trabalho de Beceiro, que menciona os problemas de Oia e Montederramo em finais do século XIII relacionando-os com a política desenvolvida por D. Dinis no conjunto do reino. Este "conseguiu moderar a ampliação do património eclesiástico" sem nunca ter posto em causa a existência do senhorio de igrejas e mosteiros, que mantiveram os seus domínios ${ }^{44}$. No século XIV, estes cenóbios sofrem, em Portugal, os mesmos problemas que na Galiza, solicitando a intervenção do monarca para terminar com os abusos dos seus funcionários ou dos concelhos ${ }^{45}$. A simultaneidade dos conflitos nos dois lados do rio Minho é perfeitamente identificável na atitude da aristocracia relativamente aos domínios monásticos. "O ataque dos senhores vassalos da zona contra os bens das duas abadias [Oia e Montederramo] enquadra-se dentro de linhas de atuação comuns a outros territórios peninsulares neste período e que está claramente documentada na Galiza e na zona do Douro" 46 .

28 A partir do século XIV, esta normalidade nas relações entre os mosteiros galegos e a coroa portuguesa é, no entanto, afetada por problemas políticos entre os reis de Portugal e de Castela. Durante as duas centúrias anteriores, os sucessivos confrontos entre os monarcas de Portugal e da Galiza, que se desenvolveram inclusive no território desta última, não implicaram nenhuma medida contra os bens eclesiásticos galegos no reino luso. A guerra entabulada por D. Afonso IV de Portugal e D. Afonso XI de Castela 
entre 1336 e 1339 foi o catalisador da mudança. Em algum momento da contenda, D. Afonso IV ordena a confiscação dos bens próprios dos naturais dos reinos do seu oponente, tal como expressa inequivocamente, em 1340, ao ordenar a restituição dos bens subtraídos de Santa Maria de Oia:

“[...] per rrason dessa gerra que ontre mjn et el rrey de Castella ouue, lles mandara tomar todallas coussas que auya no meu señorio, et emviarome pidir por merçee que, poys auya pas antre mjn et el rrey de Castella, et ennas ditas pases he contiudo que todo aquello que ffoy tomado no tenpo da gerra que antre nos ouue, que se entrege todo dũa parte et da outra a seus donos [...]"47.

Esta confiscação consta apenas para os bens de Oia ${ }^{48}$, embora se suponha - na opinião de Beceiro - que também afetariam os de Montederramo e Toxosoutos, isto é, os núcleos senhoriais ou territoriais mais destacados, deixando talvez de lado os casais e as propriedades isoladas destes e de outros cenóbios galegos. Devido à sua condição de padroado autónomo, é possível que Monte Córdova também tivesse escapado ao embargo decretado pelo rei.

A intermitente guerra luso-castelhana entre o rei D. Fernando I e os reis Enrique II e Juan I, durante a qual o rei português invadiu a Galiza, não parece ter provocado uma ordem semelhante ${ }^{49}$. Na carta de proteção que D. Fernando outorgou a Oia, em 1381, ordena que "se algũas coussas som tomadas ou embargadas de suas quimtaas e erdades que lhes façaaes loguo emtregar sem outro alguũ embargo qualquer" ${ }^{50}$. A redação deixa em aberto a possibilidade de que houvesse uma ordem real de confiscação, mas também permite entender a possibilidade de que os concelhos ou os aristocratas se tenham aproveitado da situação para usurpar os bens do mosteiro.

31 A situação muda radicalmente com a ascensão de D. João de Avis ao trono de Portugal. Em plena contenda, em 1384, o ainda pretendente ao trono concede a Diogo Nunes, comendador de Santos, "todallas rendas e foros e djreitos e trabutos que o moesteyro d'Oya, que he em Galiza, ha e tem em estes regnos" por tempo indeterminado "porquanto o dicto moesteyro sta em terra de seus Jmigos" 51 . Tal como aponta Leite Rodrigues, a atitude de D. João I muda após a Batalha de Aljubarrota - 14 de agosto -, pois em outubro de 1385 este confirma ao mosteiro galego "todos seus priujlegios, foros e liberdades e boons costumes que sempre ouuerom" ${ }^{52}$. Observa-se que D. João I limitase a confirmar os privilégios, foros ou costumes sem fazer menção expressa dos bens, que só ordena que sejam restituídos a Oia quatro anos depois, em dezembro de $1389^{53}$, mandato que se torna efetivo nas terras da Extremadura em 1390. Estas estiveram pouco tempo nas mãos dos monges, pois em 1421 ou 1422 o mosteiro enviou um dos seus monges a reclamá-las, terminando por renunciar às suas propriedades em 1434, vendendo-as ao rei D. Duarte ${ }^{54}$.

D. João I repete assim, meio século depois, os mesmos passos de D. Afonso IV: confiscar os bens durante a guerra para devolvê-los depois de esta ter terminado - à exceção, aparentemente, dos detidos pelo mosteiro de Oia na Estremadura. A partir de então, retoma-se a prática habitual da monarquia em relação aos domínios monásticos galegos em Portugal, confirmando-os e defendendo-os tal como tinham feito os seus antecessores $^{55}$.

Por outro lado, desconhecemos o que ocorreu com os outros domínios monásticos durante estas duas guerras. San Paio de Antealtares e Santa Maria de Montederramo mantêm, respetivamente, no século XV, o seu padroado sobre a igreja de São Simão de Junqueira de Mazarefes ${ }^{56}$ - que provém da remota doação condal no século X - e sobre 
Santa Maria de Cidões ${ }^{57}$. Ramirás afora normalmente bens junto a Melgaço em 1346, 1357, 1455 e 1456, mas em 1453 o mordomo do alcaide da vila devolve-lhe bens nas suas proximidades $^{58}$. Santa Baia de Donas e Santa Maria de Tomiño também aforam, em princípios do século XV, todos os seus bens portugueses a apenas a uma pessoa ${ }^{59}$. Uma estratégia comum a muitos mosteiros galegos na época consistia na doação de direitos, rendas e propriedades numa zona mais ou menos ampla a apenas uma pessoa com o objetivo de recuperar o que se tinha perdido em épocas passadas ${ }^{60}$. Esta perda de poder está relacionada não só com as usurpações, mais ou menos ocultas e importantes, como também com a própria situação das comunidades galegas, que sofrem uma crise a todos níveis durante a segunda metade do século XIV e durante todo o século XV.

O último dado sobre bens monásticos galegos em Portugal refere-se ao padroado de Monte Córdova, que Celanova acaba por perder em finais do século XV. Em 1477, a casa de S. Rosendo instaura um processo contra o duque de Guimarães e Bragança por este se ter apoderado do padroado e dos seus bens outorgando-o a um clérigo da diocese do Porto $^{61}$. A data obriga a relacionar a usurpação com a guerra entabulada entre D. Isabel e a sua sobrinha D. Joana pelo trono de Castela, ainda que a reclamação de Celanova não faça nenhuma alusão a esta guerra. O mosteiro apresenta a atuação ducal como um abuso ao instalar em Monte Córdova um clérigo da sua entourage - apesar de se tratar de uma atuação bastante habitual na Galiza daquela época, pois bispos e nobres nomeavam abades, abadessas, priores, prioresas ou párocos conforme os seus desejos e conveniências. Para além de se observar um certo desgoverno, a casa matriz desautoriza, em 1483, as ações empreendidas em Portugal por frei Jácome de Lanzá, conhecido como prior de Monte Córdova ${ }^{62}$; em 1486 o abade de Celanova nomeia o prior agostinho de Grou, Lopo Pérez Salgado, como seu procurador, vindo a excomungá-lo em 1494 por se ter apropriado indevidamente de dez mil maravedis e de "çertas escripturas et tunbos que fiaron del que eran do mosteiro de Monte Cordoba perteesçentes ao dito moesteiro de Çelanova"63.

\section{A primazia da sede bracarense}

A relação dos mosteiros galegos com Portugal não se limita apenas às propriedades que tiveram neste reino. A pertença das dioceses galegas (exceto Santiago de Compostela) à província eclesiástica bracarense até ao Cisma do Ocidente obrigava os monges do norte do Minho a atravessarem o rio para se apresentarem na sua capital metropolitana a fim de solicitarem a intervenção do seu titular em assuntos eclesiásticos da sua incumbência. Muito possivelmente, a atividade dos arcebispos de Braga nos mosteiros galegos da sua província terá sido maior do que a que a documentação, que se conserva até hoje, permite comprovar. Apesar disso, a primazia bracarense é mais patente na Galiza dos séculos XII a XIV e introduz neste trabalho cenóbios até agora não mencionados.

Os assuntos em que o arcebispo de Braga interveio em terras galegas podem ser classificados em dois grupos: os que derivam da sua autoridade como metropolitano e os encomendados pelo sumo pontífice.

O seu papel, como cabeça da metrópole bracarense, observa-se em 1209 quando o papa Inocêncio III o distingue entre o clero da sua província eclesiástica para defender a isenção que Santa Maria de Oseira, como abadia cisterciense, tinha do pagamento do dízimo eclesiástico nas terras diretamente trabalhadas pelos seus monges ${ }^{64}$. 
38 A autoridade do arcebispo, como instância superior de justiça da sua província eclesiástica, é mais notória nos pleitos que sentenciou entre os séculos XII e XIV. A primeira intervenção documentada data de 1195, quando este medeia o estabelecimento de um acordo entre o bispo de Lugo e o mosteiro de Samos em relação aos direitos diocesanos nas igrejas do couto samonense, acabando por reconhecer ao abade direitos arcediagais ${ }^{65}$. Na mesma linha, em 1298 e 1319, a mitra bracarense sentenciava a favor de Santa Maria de Oia os direitos arcediagais que lhe disputava o arcediago de Miñor nas igrejas de Mougás e de Loureza ${ }^{66}$. Para além destas, também se encontram documentadas a sentença favorável a Celanova no pleito disputado pelo vassalo Pedro Fernández pelo padroado do mosteiro de S. Salvador de Arnoia antes de 1219, a sentença a favor das monjas de Chouzán e uma sentença contra o bispo de Lugo em $1287^{67}$.

Ainda que escassas, estas sentenças mostram como o tribunal metropolitano recebe maioritariamente os pleitos em que o bispado correspondente é parte interessada, invalidando assim a possibilidade de o bispo respetivo atuar como juiz, ora como instância própria, ora como instância da parte contrária. A sua função como tribunal de apelação é demonstrada no caso de S. Salvador de Arnoia, julgado em primeira instância pelo bispo de Ourense contra o vassalo, que o leva para a alçada de Braga. A sentença proferida pelo arcebispo não foi bem aceite pelo nobre, provocando a sua excomunhão e obrigando Celanova a solicitar a D. Afonso IX a execução da sentença ${ }^{68}$.

Mais estranha ainda é a intervenção arquiepiscopal na sequência de problemas internos de um cenóbio - facto verificado apenas em Samos em meados do século XII. Por volta de 1160, o bispo de Lugo informava o seu metropolita, naquele tempo D. João Peculiar, sobre os acontecimentos ocorridos no mosteiro para que este ignorasse quem pretendia ser seu abade e não o consagrasse como tal. O resultado foi a declaração de Samos como súbdito da igreja bracarense com a obrigação de pagamento de um censo cada vez que fosse eleito um novo reitor da casa ${ }^{69}$.

41 As delegações pontifícias ao arcebispo de Braga são apenas duas e ambas estão relacionadas com questões internas de um mosteiro. A primeira, e a mais destacada, ocorreu em 1200, novamente em San Xiao de Samos, pela qual o arcebispo estava encarregado de dirimir o desacordo entre o abade e o convento relativamente aos bens correspondentes às mesas respetivas. 0 problema era antigo e provavelmente já teria sido tratado nalguma ocasião em Braga; junto com o seu deão, o arcebispo confirmou a divisão que o bispo de Lugo tinha realizado em 1167 e ditou várias normas para uma implementação correta da vida monástica samonense ${ }^{70}$.

42 A segunda encomenda pontifícia data de 1264 e nela o papa Urbano IV ordenava ao arcebispo a execução de uma ordem que já tinha sido transmitida anteriormente pelo papa Alexandre III: a de que o mosteiro de San Martiño Pinario aceitasse Juan Moogo como monge, devendo, em caso de recusa, apresentar as suas razões. O prelado devia zelar, sob apreciação prévia de Moogo, para que a abadia compostelana lhe concedesse algum benefício eclesiástico do seu património ${ }^{71}$.

43 Por último, em princípios do século XIV, a meio caminho entre o privilégio pontifício e a supremacia metropolitana, o arcebispo D. Gonçalo Pereira recebe graciosamente do papa um subsídio que deveria satisfazer todo o clero da província bracarense. A única notícia conhecida relativamente a este assunto provém do pequeno mosteiro feminino de Santa Mariña de Asadur, na diocese de Ourense que, em 1331, pedia a absolvição da excomunhão incorrida sobre a mesma ${ }^{72}$. 
44 A relação de Braga com os seus bispados sufragâneos galegos termina em finais do século XIV quando, após o Cisma do Ocidente, Portugal segue a obediência de Roma e a Galiza, juntamente com Castela, a de Avinhão, o que implicou a consequente reestruturação das províncias eclesiásticas e a concessão de Modoñedo, Lugo, Ourense, Tui e Astorga à dependência compostelana.

\section{Abades galegos como delegados pontifícios em terras de Portugal}

Continuando na esfera eclesiástica, destacamos três abades galegos a quem, por delegação do papa, foram encomendadas sete missões no reino de Portugal. Nestas missões, delimitadas num curto período cronológico de pouco mais de uma década, entre 1211 e 1222, o maior protagonista é o abade de Santa Maria de Oseira, D. Lorenzo. Este recebe seis dos sete mandatos, sempre acompanhado de, pelo menos, outro eclesiástico: quatro estão relacionados com o rei de Portugal, D. Afonso II $^{73}$, e dois com os problemas das fronteiras da diocese de Coimbra ${ }^{74}$. É neste conflito que aparece o abade de Oia, a quem é dado o encargo de- juntamente com o arcediago de Santarém e um cónego de Coimbra - resolver os problemas entre esta sede e a de Lisboa em 1216.0 terceiro abade, que pertence a Celanova, recebe com o seu prior e D. Lorenzo de Oseira, em 1222, a ordem de admoestar D. Afonso II de Portugal e os seus sequazes para que deixassem de perseguir o arcebispo de $\mathrm{Braga}^{75}$.

Esta breve temporada de presença de abades galegos em Portugal para cumprir as ordens pontifícias está assim indissoluvelmente ligada a D. Lorenzo, abade de Santa Maria de Oseira entre 1205 e 1223. De origem desconhecida, estas delegações enviadas por Roma obrigam-nos a deduzir que se trata de um nobre e a atribuir-lhe uma grande responsabilidade. Pelo seu labor em Portugal e em Oseira é distinguido como abade de Claraval em 1223. Durante três anos rege a antiga casa de $\mathrm{S}$. Bernardo, à qual renuncia em 1226, regressando a Oseira onde viria a falecer em $1238^{76}$.

\section{A presença cultural e espiritual de mosteiros galegos em Portugal}

Santa Maria de Oseira é também protagonista da única afiliação de um mosteiro português à família cisterciense. Santa Maria das Júnias é um mosteiro beneditino que, por meados do século XIII, passa para a Ordem de Cister através da casa ursariense. A mudança de observância monástica, por volta de 1245, provocou a reação da mitra de Braga que, como era habitual, não via com bons olhos a adoção dos costumes cistercienses, o que implicava uma certa imunidade relativamente à jurisdição episcopal. Graças a isto, é possível datar a época em que ocorreu a afiliação, pois em 1247 o papa ordena que o arcebispo aceite a união de Júnias a Oseira mediante um acordo que será celebrado em Chaves no ano seguinte, no qual se estabeleceram os direitos que o prelado bracarense poderia exigir-lhe dali em adiante. Na reunião, o arcebispo permitiu que um monge ursariense recebesse o abadiado de Júnias, que entra, desta forma, na ordem de Cister ${ }^{77}$.

Com esta afiliação, Oseira une-se a Celanova, reconhecida no papel de casa matriz de um cenóbio português. Para além da evidente diferença das regras entre um e outro, 
Monte Córdova parte de uma possível relação com Celanova desde tempos altomedievais, enquanto que Santa Maria das Júnias é um cenóbio que decide assumir a norma cisterciense sem nenhuma intervenção a favor ou contra por parte do rei de Portugal neste assunto. Desta forma, há que salientar a situação fronteiriça da nova casa cisterciense, de cuja conversão talvez tenhamos que responsabilizar mais os seus patronos laicos do que a sua comunidade monástica, que recebe com ela um novo abade. Chamamos também a atenção para o facto de Júnias recorrer a Oseira em vez de Montederramo, que tinha bens em Portugal, devido à fama que a casa ursariense alcançou após a estadia de D. Lorenzo em Claraval, como abade, o que a converteu num destino preferido para antigos abades de casas galegas, portuguesas e leonesas, caso de Sobrado, Alcobaça, Valparaíso e até as Júnias.

Por último, sublinhamos os intercâmbios culturais que mantiveram os mosteiros galegos com os do outro lado da fronteira. Ainda que seja um tema difícil de estudar e pouco desenvolvido, destacamos os contributos recentes de Ana Suárez González, que mostra como o Livro L - atualmente conservado em Arouca - provém de Santa Maria de Montederramo. Trata-se de um collectaneum composto de, pelo menos, duas partes: uma elaborada no cenóbio galego por volta de 1231 e a outra, talvez, na década seguinte. A autora demonstra que a sua origem está no mosteiro galego de Montederramo, onde teria permanecido até pelo menos 1258, sendo, posteriormente, levado para Arouca ${ }^{78}$. Nas palavras de Suárez, "o translado - ou translados - de um manuscrito de uma abadia a outra não deveria surpreender", uma vez que esta prática era comum entre casas da mesma ordem, neste caso cistercienses, respetivamente em 1153 e entre 1224-1226. Ambas "podem ter tido os mesmos visitantes e um desses visitantes, enviado pelo abade de Clavaral, poderia ter aproveitado para revisar, reorganizar e completar as coleções litúrgicas das duas casas"79.

\section{Conclusão}

Em resumo, a presença dominial dos mosteiros galegos em Portugal pode considerar-se episódica, exceto na própria fronteira do Minho, entre Melgaço e Caminha. Fora desta área, as suas propriedades são escassas, salvo nos casos indicados de coutos, granjas ou padroados dependentes de casas galegas. Destes, cabe destacar que são os situados na Galiza meridional que habitualmente se estendiam além-fronteiras, com a exceção de Antealtares, cujo domínio remonta aos tempos alto-medievais, e Toxosoutos.

51 Estes domínios portugueses formaram-se mediante doações de particulares que, provavelmente, na sua maioria, professavam na casa que recebia os seus bens ou então desejavam ser enterrados na sua igreja ou no seu cemitério. Grande parte destes pertenciam à aristocracia da zona, que possuía um património também transfronteiriço - como demonstrou Leite Rodrigues para Oia -, o que explica a existência das granjas lusas de Oia e de Montederramo ou a reforma cisterciense por Oseira do mosteiro beneditino das Júnias. A família cisterciense mostra-se assim especialmente capaz de atravessar a fronteira, exemplificando uma relação entre cenóbios de ambos reinos, tal como é patente no manuscrito procedente de Montederramo, atualmente no mosteiro de Arouca, estudado por Ana Suárez.

Por último, destacamos que as doações reais a mosteiros galegos foram excecionais, restringindo-se às primeiras décadas da independência portuguesa. Entre os séculos XII e XV, os domínios monásticos no reino de Portugal sofrem praticamente os mesmos 
problemas que na Galiza: são geridos de forma semelhante e a monarquia atua do mesmo modo tanto num lado do rio Minho como no outro.

Apesar disto, é evidente que a atitude da monarquia portuguesa muda nos inícios do século XIV. Pela primeira vez, D. Afonso IV toma a decisão de expropriar os bens de, pelo menos, Santa Maria de Oia, no contexto da guerra com Castela de 1336-1339, facto inédito face aos tempos anteriores. A partir deste momento, os cenóbios da Galiza são suscetíveis de sofrer represálias em Portugal porquanto o dicto moesteyro sta em terra de seus Jmigos, como disse expressamente D. João I em 1384. Apesar de o monarca recuperar, após a Batalha de Aljubarrota, o seu papel como protetor da sua igreja mosteiros galegos incluídos- não há dúvida que a relação com a Galiza sofre uma mudança evidente, que aumenta e se confirma com o Cisma do Ocidente, pondo fim aos direitos de jurisdição da província eclesiástica bracarense na Galiza.

Ainda que a fronteira se mantivesse aberta e pudesse ser facilmente atravessada em tempos de paz, a subida ao trono da casa de Avis foi indubitavelmente um marco importantíssimo para a sua história.

\section{BIBLIOGRAFIA}

Fontes manuscritas

Tui, Arquivo da Catedral, Becerro 1, fols. 44r-52v e fols. 111v-114r.

Tui, Arquivo da Catedral, Pergameos, Carpeta 10, doc. 16.

Tui, Arquivo da Catedral, Pergameos, Carpeta 12, doc. 14.

Fontes impressas

ANDRADE CERNADAS, José Miguel - O Tombo de Celanova. Santiago de Compostela: Consello da Cultura Galega, 1995.

AZEVEDO, Rui Pinto de (ed.) - Documentos medievais portugueses. Documentos régios. Vol. I: Documentos dos condes portugalenses e de D. Afonso Henriques, A.D. 1095-1185. Lisboa: Academia Portuguesa da História, 1958.

BLANCO LOZANO, Pilar - Colección diplomática de Fernando I (1037-1065). León: Centro de Estudios e Investigación San Isidoro - Archivo Histórico Diocesano, 1987.

COSTA, Avelino de Jesus da (ed.) - Liber Fidei Sanctae Bracarensis Ecclesiae. Tomo I. Braga: Assembleia Distrital, 1978.

COSTA, Avelino de Jesus da (ed.) - Liber Fidei Sanctae Bracarensis Ecclesiae. Tomo II. Braga: Junta Distrital, 1965.

COSTA, Avelino de Jesus da; MARQUES, Maria Alegria F. - Bulário Português. Inocencio III (965-1216). Coimbra: Instituto Nacional de Investigação Científica, 1989.

LA CUEVA, Benito de - Historia de los monasterios y prioratos anejos a Celanova. Edición, notas e índices por María Teresa González Balasch. Granada: Universidad de Granada, 1991. 
LORENZO, Ramón - Colección documental do mosteiro de Montederramo. Santiago de Compostela: Consello da Cultura Galega, 2016, 3 tomos.

LUCAS ÁlVAREZ, Manuel - El Tumbo de San Julián de Samos (siglos VIII-XII). Estudio introductorio. Edición diplomática. Apéndices e índices. Santiago de Compostela: Caixa Galicia, 1986.

LUCAS ÁLVAREZ, Manuel - San Paio de Antealtares, Soandres y Toques: tres monasterios medievales gallegos. Sada: Seminario de Estudios Galegos-Ediciós do Castro, 2001.

LUCAS ÁlVAREZ, Manuel; LUCAS DOMÍNGUEZ, Pedro Pablo - San Pedro de Ramirás. Un monasterio femenino en la Edad Media. Colección diplomática. Santiago de Compostela: Caixa Galicia, 1988.

MANSILLA REOYO, Demetrio - La documentación pontificia de Honorio III (1216-1227). Roma: Instituto Español de Estudios Eclesiásticos, 1965.

PICHEL GOTÉRREZ, Ricardo - Fundación e primeiros séculos do mosteiro bieito de Santo Estevo de Chouzán (sécs. IX-XIII). Noia: Toxosoutos, 2009.

PIZARRO, José Augusto de Sottomayor - Inquisitiones. Inquirições gerais de D. Dinis de 1288, sentenças de 1290 e execuções de 1291. Lisboa: Academia das Ciências de Lisboa, 2012.

Portugaliae Monumenta Historica a saeculo octavo post Christum usque ad quintundecimum. Inquisitiones. Volumen I, fasciculus III. Lisboa: Academia das Ciências de Lisboa, 1891.

Portugaliae Monumenta Historica a saeculo octavo post Christum usque ad quintundecimum. Inquisitiones. Volumen I, fasciculi IV et V. Lisboa: Academia das Ciências de Lisboa, 1897.

Portugaliae Monumenta Historica a saeculo octavo post Christum usque ad quintundecimum. Inquisitiones. Volumen I, fasciculus VIII. Lisboa: Academia das Ciências de Lisboa, 1961.

RODRÍGUEZ R. DE LAMA, Ildefonso - La documentación pontificia de Urbano IV (1261-1264). Roma: Instituto Español de Historia Eclesiástica, 1981.

ROMANÍ MARTÍNEZ, Miguel - Colección diplomática do mosteiro cisterciense de Santa Maria de Oseira (Ourense), 1025-1310. Santiago de Compostela: Departamento de Historia I, 1989.

SÁNCHEZ BELDA, Luis - Documentos reales de la Edad Media referentes a Galicia. Madrid: Dirección General de Archivos y Bibliotecas, 1953.

VAQUERO DÍAZ, María Beatriz - Colección diplomática do mosteiro de San Salvador de Celanova (ss. XIII-XV). Ourense: Concello de Celanova / Universidade de Vigo, 2004.

ZARAGOZA I PASCUAL, Ernest - "Proceso de reforma contra la abadesa de San Salvador de Albeos (1499)”. Museo de Pontevedra, 51 (1997), pp. 563-590.

Estudos

ANDRADE CERNADAS, José Miguel - El monacato benedictino y la sociedad de la Galicia medieval (siglos X al XIII). Sada: Seminario de Estudios Galegos / Ediciós do Castro, 1997.

BECEIRO PITA, Isabel - "Las tensiones en torno a los dominios del Cister gallego en el norte de Portugal”. In Actas. Congreso Internacional sobre san Bernardo e o Císter en España e Portugal. Ourense: Monasterio de Oseira, 1992, t. 1, pp. 253-265.

DURO PEÑA, Emilio - "El monasterio de Santa Marina de Asadur". Archivos Leoneses 27 (1973), pp. 309-365.

FERNANDES, A. de Almeida - "Portugal no período vimaranense (868-1128)". Revista de Guimarães 81 (1971), pp. 51-98.

GONZÁLEZ, Julio - Alfonso IX. Madrid: C.S.I.C. - Instituto Jerónimo Zurita, 1944. 
MARQUES, José - A arquidiocese de Braga no século XV. Lisboa, Imprensa Nacional / Casa da Moeda, 1988.

MARQUES, Maria Alegria F. - “A introdução da ordem de Cister em Portugal”. In La introducción del Císter en España y Portugal. Burgos: La Olmeda, 1991, pp. 163-193.

MATTOSO, José - A nobreza medieval portuguesa: a família e o poder. Lisboa: Estampa, 1987.

OTERO PIÑEYRO MASEDA, Pablo - "Ordens monásticas: o caso dos bens dos mosteiros galegos em Portugal”. In FONSECA, Luis Adão da (coord.) - Entre Portugal e a Galiza (Sécs. XI a XVII). Um olhar peninsular sobre uma região histórica. Porto: CEPESE / Fronteira do Caos Editores, 2014, pp. 201-204.

PALLARES MÉNDEZ, María del Carmen; PORTELA SILVA, Ermelindo - El bajo valle del Miño en los siglos XII y XIII. Economía agraria y estructura social. Santiago de Compostela: Universidad, 1971.

PÉREZ RODRÍGUEZ, Francisco Javier - O mosteiro de Melón no século XV. Ourense: Deputación Provincial, 1996.

PÉREZ RODRÍGUEZ, Francisco Javier - O mosteiro dos Santos Xusto e Pastor de Toxosoutos na Idade Media (séculos XII-XIII). Sada: Seminario de Estudios Galegos / Ediciós do Castro, 2002.

PÉREZ RODRÍGUEZ, Francisco Javier - "Mosteiros e priorados dependentes de San Salvador de Celanova entre 1100 y 1500". In SINGUL, Francisco (coord.) - Rudesindus. O legado do santo. Santiago de Compostela: Xunta de Galicia, 2007, pp. 204-221.

RODRIGUES, Ana Paula Leite - Senhores e camponeses num expaço de fronteira. Estudo da projecção portuguesa do domínio monástico de Santa Maria de Oia nos séculos XII a-XV). Santiago de Compostela: Facultade de Xeografia e Histoira, 2014. Tese de doutoramento.

RODRIGUES, Ana Paula Leite - Nos dois lados do rio Minho. 0 senhorio transfronteiriço do mosteiro de Santa Maria de Oia (Séculos XI a-XV). Vigo: Instituto de Estudios Vigueses, 2017.

ROMANÍ MARTÍNEZ, Miguel - El monasterio de Santa Maria de Oseira (Ourense). Estudio histórico (1137-1310). Santiago de Compostela: Universidade, 1989.

SILVA, Manuela Santos - Óbidos e a sua região na Baixa Idade Media. Lisboa: Universidade de Lisboa, 1996. Tese de Doutoramento.

SOUSA, Bernardo Vasconcelos e (Dir.) - Ordens religiosas em Portugal. Das origens a Trento - Guia Histórico. Lisboa: Livros Horizonte, 2005.

SUÁREZ GONZÁLEZ, Ana - "Cistercian Scriptoria in the Twelfth and Thireenth Centuries. A Starting Point”. In D'EMILIO, James (coord.) - Culture and Society in Medieval Galicia. A Cultural Crossroads at the Edge of Europe. Leiden-Boston: Brill, 2015, pp. 765-811.

\section{NOTAS}

1. PALLARES MÉNDEZ, María del Carmen; PORTELA SILVA, Ermelindo - El bajo valle del Miño en los siglos XII y XIII. Economía agraria y estructura social. Santiago de Compostela: Universidad, 1971.

2. PÉREZ RODRÍGUEZ, Francisco Javier - 0 mosteiro dos Santos Xusto e Pastor de Toxosoutos na Idade Media (séculos XII-XIII). Sada: Seminario de Estudios Galegos-Ediciós do Castro, 2002.

3. RODRIGUES, Ana Paula Leite - Nos dois lados do rio Minho. O senhorio transfronteiriço do mosteiro de Santa Maria de Oia (Séculos XI a-XV). Vigo: Instituto de Estudios Vigueses, 2017.

4. A quem agradeço desde já por ter-me permitido utilizar documentação inédita da sua tese doutoral. 
5. LUCAS ÁLVAREZ, Manuel - San Paio de Antealtares, Soandres y Toques: tres monasterios medievales gallegos. Sada: Seminario de Estudios Galegos-Ediciós do Castro, 2001, pp. 175-177. Ver também MATTOSO, José - A nobreza medieval portuguesa: a família e o poder. Lisboa: Estampa, 1987, pp. 113-114 e p. 143 n. e FERNANDES, A. de Almeida - "Portugal no período vimaranense (868-1128)". Revista de Guimarães 81 (1971), p. 231, p. 242 e p. 251n.

6. ANDRADE CERNADAS, José Miguel - El monacato benedictino y la sociedad de la Galicia medieval (siglos X al XIII). Sada: Seminario de Estudios Galegos-Ediciós do Castro, 1997, p. 90.

7. “[...] ut illas villas que sunt in ripa Limie quas ille comite domino Tello Eleutiz testauit ad monasterium, nominata Paratella et Ponte, tertia ex ea, et Mazarefes [...]" (BLANCO LOZANO, Pilar - Colección diplomática de Fernando I (1037-1065). León: Centro de Estudios e Investigación San Isidoro - Archivo Histórico Diocesano, 1987, pp. 188-190 (doc. n. 75) e, parcial, em LUCAS ÁLVAREZ, Manuel - San Paio de Antealtares, Soandres y Toques, pp. 177-178).

8. Freguesia de Feitosa, concelho de Ponte de Lima; São Mamede de Este é freguesia do concelho de Braga.

9. "[...] in villa Domez casal de Abbatibus, quod est circa ipsam ecclesiam, quod dedit comes domnus Telus cum aliis suis hereditatibus eidem Antealtarium monasterio [...]" (COSTA, Avelino de Jesus da (ed.) - Liber Fidei Sanctae Bracarensis Ecclesiae. Tomo I. Braga: Assembleia Distrital, 1978, p. 258 (doc. n. 825).

10. AZEVEDO, Rui Pinto de (ed.) - Documentos medievais portugueses, p. 114 (doc. n. 91), e LORENZO, Ramón - Colección documental do mosteiro de Montederramo. Santiago de Compostela: Consello da Cultura Galega, 2016. 3 tomos, pp. 185-186 (doc. n. 5).

11. Ainda que Cister não permitisse a criação de padroados, é com o título de granja que partilha Santa Maria de Cidões a partir do final do século XIII, quando em 1294 o prior de Cidões, Johan Parente, aparece como testemunha num foro. Naquele tempo, a granja não era propriedade exclusiva de Montederramo, mas sim partilhada com o seu irmão cisterciense de Valparaíso, o qual permutou a sua parte com o mosteiro galego em 1298, entregando Montederramo em troca das casas que possuía na cidade de Zamora "a la collaçion de San Johan de Puerta Nueua", e três mil maravedis (LORENZO, Ramón - Colección documental do mosteiro de Montederramo, pp. 717 e pp. 771-773 (docs. n. 548 y 605).

12. Em 1355, uma sentença sobre a granja mostra como se exerce a jurisdição na freguesia, confirmando-se a jurisdição do mosteiro em Cidões e Vilar de Peregrinos, mas não nos casais isolados (BECEIRO PITA, Isabel - "Las tensiones en torno a los dominios del Cister gallego en el norte de Portugal". In Actas. Congreso Internacional sobre san Bernardo e o Císter en España e Portugal. Tomo 1, Ourense: Monasterio de Oseira, 1992, pp. 253-265, p. 257; no documento em LORENZO, Ramón Colección documental do mosteiro de Montederramo, pp. 1735-1737, (doc. n. 1359).

13. A doação de D. Afonso Henriques a Montederramo - da Ribeira de Solar, da igreja de São João da Cova, em terras de Vieira, e do couto de Padornelo, em terras de Coura - datada no mesmo dia que a doação a D. Fernando Anáiaz em Penhas Juntas foi demonstrada como falsa por AZEVEDO, Rui Pinto de (ed.) - Documentos medievais portugueses, pp. 115-116 (doc. n. 93), o que não informa LORENZO, Ramón - Colección documental do mosteiro de Montederramo, pp. 184-185 (doc. n. 4).

14. Em relação ao domínio de Toxosoutos sobre Paredes, PÉREZ RODRÍGUEZ, Francisco Javier - 0 mosteiro dos Santos Xusto e Pastor de Toxosoutos, p. 60 y pp. 92-93.

15. Não há registo da doação, mas sim de uma inquirição dos bens de Oia ordenada por Sancho II em 1235, onde se averiguou, nas palavras de Ana Paula Leite, que "o mosteiro de Oia possuía uma herdade, a da Fanga da Fé, doada por D. Afonso Henriques e D. Sancho I, e confirmada por D. Sancho II" (RODRIGUES, Ana Paula Leite - Nos dois lados do rio Minho, pp. 130-31).

16. RODRIGUES, Ana Paula Leite - Nos dois lados do rio Minho, pp. 50-54, pp. 99-124.

17. RODRIGUES, Ana Paula Leite - Nos dois lados do rio Minho, pp. 159-163.

18. RODRIGUES, Ana Paula Leite - Nos dois lados do rio Minho, p. 161. 
19. SILVA, Manuela Santos - Óbidos e a sua região na Baixa Idade Media. Lisboa: Universidade de Lisboa, 1996. Tese de Doutoramento.

20. Especialmente importantes parecem ser os bens doados em Coimbra e arredores, e também em Leça, futura Leça do Balio, perto do Porto; de todas as doações em terras portuguesas a que mais se destaca é a realizada por Adosinda Gutiérrez e seu marido Jimeno Díaz, em 950 (ANDRADE CERNADAS, José Miguel - O Tombo de Celanova. Santiago de Compostela: Consello da Cultura Galega, 1995, pp. 7-13, pp. 17-21, p. 110, pp. 112-115, pp. 240-241 e pp. 692-693 (docs. n. 2, 4, 71, 73, $74,75,172,500)$.

21. ANDRADE CERNADAS, José Miguel - O Tombo de Celanova, p. 111 e p. 178 (docs. n. 72 e 116).

22. "[...] in Caminia hereditates quod fuerunt de genitrici mea comitissa domna Gunterote qui prius uobis concessit et nos de iuri vestro obtinuimus usque modo cum adiunctionibus sus ab integro; habent iacentia litore maris ubi se infundet Minei in ipsius mare[...]" (ANDRADE CERNADAS, José Miguel - 0 Tombo de Celanova, p. 430 (doc. n. 291).

23. Sobre este padroado, ver PÉREZ RODRÍGUEZ, Francisco Javier - "Mosteiros e priorados dependentes de San Salvador de Celanova entre 1100 y 1500". In SINGUL, Francisco (coord.) Rudesindus. O legado do santo. Santiago de Compostela: Xunta de Galicia, 2007, pp. 204-221, pp. 211-214.

24. LA CUEVA, Benito de - Historia de los monasterios y prioratos anejos a Celanova. Edición, notas e índices por María Teresa González Balasch. Granada: Universidad de Granada, 1991, pp. 94-95.

25. "Hic incipit inquisitio Ecclesie Sancti Salvatoris de Monte Corduba et omnium parrochianorum ejusdem ecclesie. Martinus Petri, juratus et interrogatus cujas est ipsa Ecclesia, dixit quod est Domini Regis, et ad presentacionem Domini Regis Bracharensis Archiepiscopus priorem constituit in eadem [...]" (Portugaliae Monumenta Historica a saeculo octavo post Christum usque ad quintundecimum. Inquisitiones. Volumen I, fasciculi IV et V. Lisboa: Academia das Ciências de Lisboa, 1897, p. 541). Apesar de aparecer como ecclesia, ainda que fosse dirigida por um prior, nas inquirições costuma referir-se a Monte Córdova como monasterium (p. 527, p. 528, p. 534, p. 537).

26. "Freyguesia de $<$ San Salvador de $>$ Monte Cordova a hy huum couto per padrões dessa egreja e d'ouvida dizem que o coutou Rey mays non sabem qual. + Este como esta sabha el Rey mays do couto se quiser." (PIZARRO, José Augusto de Sottomayor - Inquisitiones. Inquirições gerais de D. Dinis de 1288, sentenças de 1290 e execuções de 1291. Tomo 2. Lisboa: Academia das Ciências de Lisboa, 2012, p. 15).

27. “[...] por quanto seendo a dita sua igreja do nosso padroado et da coroa do nosso regno et o castello de Castlo Leboreiro do moesteiro de Cellanova en tempo dos reys dom Afomso que de que foy de Bellonha et del rey don Sancho que foram reis destos nossos regnos fora grande letigio ante ellos et o dito moesteiro de Celanova sobre o dito castello de Castro Leboreiro et fora feita huna aveença et conposyçom antre os ditos reis et o dito moesteiro de Celanova em maneira descanbo, dando os ditos reis a dita sua igreja de Monte Cordova ao dito moesteiro de Çellanova e o padroado della con todollos dereitos et perteenças que em ella aviam et com biint marabedis de colheita que tanbem hy avia, et geeralmente com todo sem $\mathrm{t}[$...] ]arem nem reservarem para a coroa de nossos regnos coussa alguna [...]" (VAQUERO DÍAZ, María Beatriz - Colección diplomática do mosteiro de San Salvador de Celanova (ss. XIII-XV). Tomo 2. Ourense: Concello de CelanovaUniversidade de Vigo, 2004, pp. 138-140 (doc. n. 494).

28. Em 1502, o cabido tudense fazia uma pesquisa dos bens portugueses do suprimido mosteiro de Tomiño nas freguesias de São Gião de Badim, São Salvador de Mujuzão -hoje desaparecida-, São Paio de Segude, São Salvador de Barbeita, São Tiago de Penso, São Pedro de Riba de Mouro, Santa Marinha de Prozelo, São Salvador da Granda, Santa Baia de Cerdal, São Miguel de Fontoura, São Felix de Candemil - naquele tempo São Pedro Fiz de Moreira-, Santa Baia de Gondar, São Salvador de Covas, São Pantaleão de Cornes, São Paio de Vila Meã, São João de Campos, São João de Revoreda, Santa Maria de Lovelhe, São Paio de Moledo, São Tiago de Crestelo, São Martinho de 
Lanhelas e São Pedro das Seixas nos termos de Valadares, Monção, Valdevez, Valença do Minho, Vila Nova da Cerveira e Caminha -com casas nesta vila-, assim como nas freguesias, já no bispado do Porto, de São Cosme de Gondomar, Santa Maria de Alvarelhos e São Martinho de Guilhabreu, e as de São Martinho de Escariz e Santo Estêvão de Riba do Neiva, respetivamente dos termos de Vila Verde e Ponte de Lima (Tui, Arquivo da Catedral, Becerro 1, fols. 44v-51v). Em finais do século XIII constam, nas Inquirições de 1288, propriedades de Tomiño nas freguesias de Reboreda, Vila Meã, Candemil e São Cosme de Gondomar (PIZARRO, José Augusto de Sottomayor Inquisitiones. Inquirições gerais de D. Dinis de 1288, t.1, pp. 136-137, p. 143 e p. 280; e t. 2, p. 41).

29. Portugaliae Monumenta Historica a saeculo octavo post Christum usque ad quintundecimum. Inquisitiones. Volumen I, fasciculus III. Lisboa: Academia das Ciências de Lisboa, 1891, p. 351 e p. 356. 30. Tui, Arquivo da Catedral, Becerro 1, fol. 49r e fols. 111v-114r.

31. LUCAS ÁlVAREZ, Manuel; LUCAS DOMínGUEZ, Pedro Pablo - San Pedro de Ramirás. Un monasterio femenino en la Edad Media. Colección diplomática. Santiago de Compostela: Caixa Galicia, 1988 , p. 202, p. 460 , p. 497 , p. 512 , p. 576 e p. 579 (docs. n. $24,264,307,308,327,482$ e 490).

32. ZARAGOZA I PASCUAL, Ernest - "Proceso de reforma contra la abadesa de San Salvador de Albeos (1499)". Pontevedra. Museo de Pontevedra 51 (1997), pp. 563-590, pp. 570-571.

33. BECEIRO PITA, Isabel - "Las tensiones en torno a los dominios del Cister gallego en el norte de Portugal", pp. 253-265, p. 254.

34. LORENZO, Ramón - Colección documental do mosteiro de Montederramo, p. 1039, p. 1048, pp. 1061-1062, pp. 1648-1649, pp. 1669-1671 (docs. n. 830, 837, 851, 1296, 1313 e 1314).

35. “[...] Et scit quod villa de Mayros, que est terminus de Portugalie et solebat uenire ad iudicium judicis de Rio Liure, et modo non uenit ibi nisi quando uoluerint, quia defendit monasterium de Villaza, que est de Legione, et Aluarus Petri, miles, et donna Orraca Ermigiz, et filiis de Petro Garsie et sus fraternitas, et non obediunt de illa domino regi Portugalie nisi quod derunt monetam quando rex mandauit sacare [...]" (Portugaliae Monumenta Historica a saeculo octavo post Christum usque ad quintundecimum. Inquisitiones. Volumen I, fasciculus VIII. Lisboa: Academia das Ciências de Lisboa, 1961, p. 1347).

36. Portugaliae Monumenta Historica a saeculo octavo post Christum usque ad quintundecimum. Inquisitiones. Volumen I, fasciculus VIII, p. 1363; e PIZARRO, José Augusto de Sottomayor Inquisitiones. Inquirições gerais de D. Dinis de 1288, t. 2, p. 213.

37. RODRIGUES, Ana Paula Leite - Nos dois lados do rio Minho, pp. 98-103 e pp. 241-280.

38. RODRIGUES, Ana Paula Leite - Nos dois lados do rio Minho, p. 138.

39. $O$ interesse de Toxosoutos por Paredes estaria na exploração de sal (PÉREZ RODRÍGUEZ, Francisco Javier, O mosteiro dos Santos Xusto e Pastor de Toxosoutos, p. 60) que também obteria Oia em Atouguia da Baleia (RODRIGUES, Ana Paula Leite - Senhores e camponeses num expaço de fronteira. Estudo da projecção portuguesa do domínio monástico de Santa Maria de Oia nos séculos XII a XV). Santiago de Compostela: Facultade de Xeografia e Histoira, 2014. Tese de doutoramento, pp. 196-199).

40. RODRIGUES, Ana Paula Leite - Nos dois lados do rio Minho, pp. 139-146.

41. A título de exemplo, do couto de Parede a Toxosoutos em 1184 e 1224 (PÉREZ RODRÍGUEZ, Francisco Javier - O mosteiro dos Santos Xusto e Pastor de Toxosoutos, p. 92)

42. Isenção de portagem em Oia em 1245; reconhecimento de que este mosteiro não devia satisfazer colheita ao rei em 1282; a carta de proteção ao mosteiro em 1326 (RODRIGUES, Ana Paula Leite - Nos dois lados do rio Minho, pp. 184, pp. 187-188, pp. 195-196 e pp. 200-201); ordem para rever e manter os privilégios de Montederramo em Cidões e noutras localidades em 1335 (SÁNCHEZ BELDA, Luis - Documentos reales de la Edad Media referentes a Galicia. Madrid: Dirección General de Archivos y Bibliotecas, 1953, p. 456 (doc. n. 1077); confirmação da isenção de colheita de Monte Córdova em 1460 (VAQUERO DÍAZ, María Beatriz - Colección diplomática do mosteiro de San Salvador de Celanova, t. 2, pp. 138-139 (doc. n. 494). 
43. FONSECA, L. Adão da (coord.) - Entre Portugal e a Galiza (Sécs. XI a XVII). Um olhar peninsular sobre uma região histórica. Porto: CEPESE / Fronteira do Caos Editores, 2014, pp. 203-204; BECEIRO PITA, Isabel - "Las tensiones en torno a los dominios del Cister gallego en el norte de Portugal", passim.

44. BECEIRO PITA, Isabel - "Las tensiones en torno a los dominios del Cister gallego en el norte de Portugal", pp. 255-256.

45. BECEIRO PITA, Isabel - "Las tensiones en torno a los dominios del Cister gallego en el norte de Portugal", pp. 257-259.

46. BECEIRO PITA, Isabel - "Las tensiones en torno a los dominios del Cister gallego en el norte de Portugal", p. 259.

47. RODRIGUES, Ana Paula Leite - Nos dois lados do rio Minho, p. 203.

48. Em 1340, os bens imóveis são restituídos a Oia e, em 1342, "os gaados et cubas et arquas et outras louças" que o almoxarife de Valença "mantinha ffillhadas" (RODRIGUES, Ana Paula Leite Nos dois lados do rio Minho, pp. 203-204).

49. RODRIGUES, Ana Paula Leite - Nos dois lados do rio Minho, pp. 214-219.

50. “[...] se algũas coussas som tomadas ou embargadas de suas quimtaas e erdades que lhes façaaes loguo emtregar sem outro alguũ embargo qualquer, nom embargamdo quaaesquer cartas ou mandados que aiades em comtrairo desto, ou ouuerdes ao diamte, por quanto nossa merçee he que lhe nom sseia filhado nehuũa coussa que aia em nossos regnos como dito he [...]" (RODRIGUES, Ana Paula Leite - Senhores e camponeses num expaço de fronteira, p. 258).

51. RODRIGUES, Ana Paula Leite - Nos dois lados do rio Minho, p. 222.

52. RODRIGUES, Ana Paula Leite - Nos dois lados do rio Minho, p. 223.

53. RODRIGUES, Ana Paula Leite - Nos dois lados do rio Minho, pp. 223-226.

54. Entretanto, em 1426, D. João I entregou-os ao seu copeiro-mor. Note-se que se refere à granja de Fanga da Fé e não às restantes propriedades na zona que nunca foram restituídas ao mosteiro (RODRIGUES, Ana Paula Leite - Nos dois lados do rio Minho, pp. 175-178 e pp. 228-229).

55. RODRIGUES, Ana Paula Leite - Nos dois lados do rio Minho, pp. 226-236. Ao longo da sua obra, a autora (tenta) relacionar e explicar cada um dos documentos reais expedidos a favor do mosteiro em função da situação política do momento entre Portugal e Castela. Isto levou-a a longas observações sobre as mudanças de opinião de um e do outro monarca como, por exemplo, a sua surpresa perante a entrega dos bens estremenhos do mosteiro por D. João I de Portugal ao seu copeiro em 1426: "Que razões poderiam justificar a acusação dirigida ao abade do mosteiro de Oia a quem, com anterioridade, o rei tanto tinha beneficiado e, inclusivamente, ordenado a devolução de parte dos bens que agora lhe embargava?" (pp. 268-270). A verdade é que os benefícios não foram tantos, mas sim as ações habituais da monarquia - neste caso a portuguesa, como também podia ter sido a galega ou castelhana - em relação a um mosteiro com propriedades no seu reino. Ainda que justificados em alguns casos, acho que estas suposições são, em geral, excessivamente artificiais. 0 melhor exemplo seria a restituição da granja de Silva a Oia por ordem de D. Afonso V, em 1455, que a autora relaciona com o então recente matrimónio contraído entre D. Joana de Portugal e Enrique IV de Castela (pp. 235-238), quando o documento que ela mesma edita - mostra claramente que o monarca simplesmente impede a usurpação à força de metade da granja por Antón Gómez de Abreu, que "ameaçara tanto seu abade dizendo que se lhe nom enprazaua a meatade da dita granja e beens a ella pertençentes que o mandaria matar e que o dito abade com temor lhe fezera o dito enprazamento" (RODRIGUES, Ana Paula Leite - Senhores e camponeses num expaço de fronteira, pp. 724-726, doc. n. 197).

56. MARQUES, José - A arquidiocese de Braga no século XV. Lisboa: Imprensa Nacional - Casa da Moeda, 1988, p. 1085.

57. LORENZO, Ramón - Colección documental do mosteiro de Montederramo, pp. 2229-2231 (doc. n. 1649). 
58. LUCAS ÁlVAREZ, Manuel; LUCAS DOMíngueZ, Pedro Pablo - San Pedro de Ramirás, pp. 497-498, p. 512, p. 576 e p. 579 (docs. n. 308, 327, 482, 490 e 492).

59. Em 1430, o mosteiro de Donas autoriza Rodrigo Fernández a recuperar e gerir os seus bens em Portugal. Por sua vez, Tomiño afora todos os seus bens em Portugal a Rodrigo López de Vilanova em 1427 e também ao seu filho Lopo Rodríguez em 1449 quando acompanha a abadessa a Ponte de Lima para confirmar um inventário de bens e rendas do cenóbio (Tui, Arquivo da Catedral, Pergameos, Cp. 10, n. 16; Pergameos, Cp. 12, n. 14; Becerro I, fol. 44rv, fol. 51rv, fol. 52rv e fol. 113rv). 60. A título de exemplo, o foro que, em 1478, Santa Maria de Melón concede ao escudeiro Luís de Vilamarín do couto de Pereiras para que descubra o que está negado y ocultado della, renovando um foro feito nas mesmas circunstâncias nas décadas anteriores a Afonso Ouxea de Vilamarín e a Sueiro de Vilamarín, talvez pai ou avô do novo foreiro (PÉREZ RODRÍGUEZ, Francisco Javier - 0 mosteiro de Melón no século XV. Ourense: Deputación Provincial, 1996, p. 32).

61. VAQUERO DÍAZ, María Beatriz - Colección diplomática do mosteiro de San Salvador de Celanova, t. 2, pp. 360-362 (doc. n. 660).

62. VAQUERO DÍAZ, María Beatriz - Colección diplomática do mosteiro de San Salvador de Celanova, t. 3, pp. 360-362 (doc. n. 660).

63. VAQUERO DÍAZ, María Beatriz - Colección diplomática do mosteiro de San Salvador de Celanova, t. 3, pp. 78-79 e pp. 335-336 (docs. n. 780 e 886).

64. ROMANÍ MARTÍNEZ, Miguel - Colección diplomática do mosteiro cisterciense de Santa María de Oseira (Ourense), 1025-1310. Santiago de Compostela: Departamento de Historia I, 1989, pp. 137-139 (docs. n. 127 e 128).

65. Este acordo é um dos acontecimentos que marcam o longo conflito entre Samos e a sua catedral diocesana, que se desenvolve durante o século XII e a primeira metade do século XIII, terminando com o reconhecimento do abade de Samos como arcediago do seu couto em 1250 (ANDRADE CERNADAS, José Miguel - El monacato benedictino y la sociedad de la Galicia medieval, pp. 185-187; no documento em LUCAS ÁLVAREZ, Manuel - El Tumbo de San Julián de Samos (siglos VIIIXII). Estudio introductorio. Edición diplomática. Apéndices e índices. Santiago de Compostela: Caixa Galicia, 1986, pp. 145-148 (doc. n. 49).

66. RODRIGUES, Ana Paula Leite - Nos dois lados do rio Minho, pp. 283-285.

67. GONZÁLEZ, Julio - Alfonso IX. Madrid: CSIC-Instituto Jerónimo Zurita, 1944, pp. 497-498 (doc. n. 383); e PICHEL GOTÉRREZ, Ricardo - Fundación e primeiros séculos do mosteiro bieito de Santo Estevo de Chouzán (sécs. IX-XIII). Noia: Toxosoutos, 2009, pp. 208-210 (doc. n. 57).

68. GONZÁLEZ, Julio - Alfonso IX, pp. 497-498 (doc. n. 383).

69. COSTA, Avelino de Jesus da (ed.) - Liber Fidei Sanctae Bracarensis Ecclesiae, tomo I, pp. 242-244 (doc. n. 210) e tomo II, pp. 76-77 (doc. n. 342); também em LUCAS ÁLVAREZ, Manuel - El Tumbo de San Julián de Samos, pp. 478-480 (docs. n. S-25 e S-26).

70. LUCAS ÁlVAREZ, Manuel - El Tumbo de San Julián de Samos, pp. 152-153 (doc. n. 52).

71. RODRÍGUEZ R. DE LAMA, Ildefonso - La documentación pontificia de Urbano IV (1261-1264). Roma: Instituto Español de Historia Eclesiástica, 1981, pp. 405-406 (doc. n. 300).

72. DURO PEÑA, Emilio - “El monasterio de Santa Marina de Asadur". Archivos Leoneses 27 (1973), pp. 309-365, pp. 340-341, doc. n. 16.

73. COSTA, Avelino de Jesus da; MARQUES, Maria Alegria F. - Bulário Português. Inocencio III (965-1216). Coimbra: Instituto Nacional de Investigação Científica, 1989, pp. 331-333, pp. 348-349 e 357-358 (docs. n. 183, 194 e 201), e MANSILLA REOYO, Demetrio - La documentación pontificia de Honorio III (1216-1227). Roma: Instituto Español de Estudios Eclesiásticos, 1965, p. 285 (doc. n. 383).

74. COSTA, Avelino de Jesus da; MARQUES, Maria Alegria F. - Bulário Português. Inocencio III, pp. 305 e 378-379 (docs. n. 160 e 215).

75. MANSILLA REOYO, Demetrio - La documentación pontificia de Honorio III, pp. 301-302 (doc. n. 407). 
76. Sobre D. Lorenzo, ROMANí MARTÍNEZ, Miguel - El monasterio de Santa María de Oseira (Ourense). Estudio histórico (1137-1310). Santiago de Compostela: Universidade, 1989, pp. 73-106.

77. MARQUES, Maria Alegria F. - “A introdução da ordem de Cister em Portugal”. In La introducción del Císter en España y Portugal. Burgos, La Olmeda, 1991, pp. 163-19, p. 175. Contudo, no ano seguinte - em 1248 - Inocencio IV ordenava ao arcebispo de Braga que Júnias - dirigido por um monge de Oseira - fosse unido a Santa Maria de Bouro (COSTA, Avelino de Jesus da (ed.) Liber Fidei Sanctae Bracarensis Ecclesiae, tomo II, pp. 347-348 (doc. n. 903). A adscrição do mosteiro de Santa Maria das Júnias, perto de Pitões das Júnias a um ou a outro durante entre os séculos XIII a XV é um tema que espera uma investigação minuciosa; um resumo da sua história pode ser lido em SOUSA, Bernardo Vasconcelos e (dir.) - Ordens religiosas em Portugal. Das origens a Trento Guia Histórico. Lisboa: Livros Horizonte, 2005, pp. 109-110.

78. SUÁREZ GONZÁLEZ, Ana - "Cistercian Scriptoria in the Twelfth and Thirteenth Centuries. A Starting Point”. In D’EMILIO, James (coord.) - Culture and Society in Medieval Galicia. A Cultural Crossroads at the Edge of Europe. Leiden-Boston: Brill, 2015, pp. 765-811, pp. 771-776.

79. SUÁREZ GONZÁLEZ, Ana - "Cistercian Scriptoria in the Twelfth and Thirteenth Centuries. A Starting Point", p. 776.

\section{RESUMOS}

O presente trabalho identifica os mosteiros galegos que tiveram bens no reino de Portugal, entre os séculos XII e XV, para depois analisar e caracterizar esses bens. A política seguida pelos monarcas portugueses em relação a estes mosteiros e aos seus bens é também objeto de estudo, observando-se a importância que para essa relação tiveram as vicissitudes políticas que os reis de Portugal enfrentaram com os da Galiza. Também se estudam as relações mantidas pelos monges e mosteiros galegos com o reino vizinho a nível eclesiástico: basicamente, os dados existentes sobre os seus recursos à sede arcebispal de Braga - que foi a sua metropolitana até ao Cisma do Ocidente - bem como as delegações pontifícias a abades galegos para intervir em questões portuguesas. Por último, referir-nos-emos brevemente ao papel cultural e espiritual que tiveram os mosteiros galegos no reino vizinho.

This paper identifies the Galician monasteries with real estate in the Kingdom of Portugal between the 12th and 15th centuries and analyses and characterizes such property. The policy of Portuguese monarchs regarding such property is also analysed while paying particular attention to political relations between Portuguese and Spanish kings. The ecclesiastical relations between Galician monasteries and the neighbouring kingdom are also subject of study: basically, the existing data at the archbishop's see of Braga -metropolitan see up to the Western Schism - and the pontifical authorization granted to Galician abbots to intervene in Portuguese affairs. Finally, a brief reference is made to the cultural and spiritual role of Galician monasteries in the neighbouring kingdom.

\section{ÍNDICE}

Keywords: Galicia, Portugal, monasteries, boundary

Palavras-chave: Galiza, Portugal, mosteiros, fronteira 


\section{AUTOR}

\section{FRANCISCO JAVIER PÉREZ RODRÍGUEZ}

Universidade de Vigo. Facultade de Historia, 32004 Ourense, España. fjperez@uvigo.es. https:// orcid.org/0000-0002-1600-3084 